\title{
O POPULAR E O UNIVERSAL EM O BOI VELHO DE SIMÃO LOPES NETO THE POPULAR AND THE UNIVERSAL IN O BOI VELHO BY SIMÃO LOPES NETO
}

\author{
Recebido: 04/05/2020 | Aprovado: 25/05/2020 | Publicado: 10/07/2020 \\ DOI: https://doi.org/10.18817/rlj.v4i1.2272
}

\author{
Poliana Bernabé Leonardeli ${ }^{1}$ \\ Orcid ID: https://orcid.org/0000-0003-4534-474X
}

\begin{abstract}
Resumo: A proposta do artigo é abordar mais detidamente o conto $O$ Boi Velho do gaúcho Simão Lopes Neto, destacando temáticas importantes da cultura popular presentes nele, mas salientando também a presença de características universais da literatura ao longo do enredo. Escrito no início do século $X X$, o autor utiliza na proposta narrativa do conto linguagem e temáticas, até então, estranhas ao mundo acadêmico brasileiro, mas que, em pouco tempo, após a semana de Arte Moderna, principalmente, serão inalienáveis da tradição literária nacional. Simão Lopes Neto foi, desse modo, um dos primeiros autores brasileiros a universalizar a linguagem e as temáticas oriundas da cultura popular, e faz-se relevante analisar em sua obra essa faceta.
\end{abstract}

Palavras-chave: Cultura Popular. Literatura Universal. Literatura Brasileira

Abstract: The purpose of the article is to approach the tale O Boi Velho by the gaucho Simão Lopes Neto in more detail, highlighting important themes of popular culture present in it, but emphasizing the presence of universal characteristics of literature in its plot. Written in the early twentieth century, the author uses in the narrative proposal of the tale language and themes, until then, foreign to the Brazilian academic world, but which, shortly, after the week of Modern Art, mainly, will be inalienable from the national literary tradition. Simão Lopes Neto was, thus, one of the first Brazilian authors to universalize the language and themes from popular culture, and it is relevant to analyze this aspect in his work.

Keywords: Popular Culture. Universal Literature. Brazilian literature

\section{Introdução}

O início do século $X X$ foi marcado por mudanças que afetaram 0 comportamento político-social do nosso tempo. Mediante todo o acúmulo de acontecimentos pertencentes a esse período, cheio de contradições e complexidades, foi possível aos artistas em geral encontrar um terreno farto para a

\footnotetext{
${ }^{1}$ Mestre em estudos literários pela UFES. Professora adjunta da Faculdade de Ensino Superior de Linhares (FACELI). Possui artigos publicados na área de Literatura, Literatura Infanil e juvenil e Formação Leitora. Dedica-se a pesquisar a cultura popular, a memória e a identidade cultural presentes em produções da literatura infantil e juvenil e demais literaturas e o ensino de leitura e escrita em ambiente escolar. E-mail: pleonardeli@gmail.com
} 
criação de novos conceitos no campo da arte, o que causou nos espaços acadêmicos forte efervescência.

$\mathrm{Na}$ Europa, as artes plásticas, primeiramente, em movimentos de vanguarda distintos trouxeram propostas que, em geral, buscavam desorganizar a cultura, em especial a arte produzida até então. A proposta era radical, pretendiase criar uma arte totalmente nova, mas nem por isto os vanguardistas deixaram de se inspirar em estilos anteriores (REGO, 2002).

Na literatura nacional, o impacto dessas mudanças foi imenso, uma vez que aqui as publicações seguiam modelos europeus. O divisor de águas na produção artística brasileira ocorre em 1922, na Semana de Arte Moderna, quando, pela primeira vez, a literatura de vanguarda ali apresentada, inovou principalmente no uso da linguagem e nas temáticas, embora ainda pautada nos principais movimentos artísticos europeus.

As obras expostas na Semana de Arte Moderna procuraram representar os mais diversos aspectos da cultura e da sociedade brasileira, indo ao encontro de um Brasil mais profundo e, até então, estranho aos meios literários eruditos. Porém, antes disso, alguns autores que produziam literatura fora do eixo acadêmico localizado entre Rio e São Paulo, já buscavam, mesmo que inconscientemente, em suas produções, inovações como as que viriam a se tornar tão comuns a partir da Semana de Arte Moderna. Um deles foi o gaúcho Simão Lopes Neto.

O objetivo, neste artigo, é analisar mais detidamente um conto desse autor, O Boi Velho, uma vez que Lopes pode ser, segundo Zalla (2010), caracterizado como um pesquisador rigoroso, de estilo refinado, que em posse dessas qualidades retrata o imaginário popular em canções e poemas do Cancioneiro Gaúcho, dando forma à linguagem e à vida da gente do campo, tudo isso, antes que esses recursos se tornassem corriqueiros nas produções nacionais.

A obra inovadora do autor do ponto de visto temático e linguístico foi produzida fora dos eixos acadêmico e econômico do período e antes do movimento modernista ser tendência em território nacional. Cabe dar relevo, então, a sua escrita, bem como destacar, neste trabalho, alguns aspectos dos estudos acerca da cultura popular, iniciados mais efetivamente a partir do século XVIII.

Mas, como pretendemos apontar, a despeito de sua relação com a cultura popular, a obra de Simões Lopes Neto ultrapassa o mero fato regional e alcança 
uma qualidade literária inerente aos clássicos: a universalidade. A linguagem coloquial, o aproveitamento do folclore, o processo de animalização da natureza, a humanização das personagens são recursos que identificam o estilo de Simões Lopes Neto e convergem para estabelecer a marca de identidade do seu mundo de ficção: a mescla entre o real e o fantástico (CHAVES, 2001).

Esses atributos presentes em sua escrita reaparecerão em obras de tantos outros autores nacionais ao longo do século. Por esse motivo, torna-se relevante analisar a escrita de Simão Lopes Neto, uma vez que o autor reúne todo o universo folclórico e linguístico da região em que viveu a um olhar reflexivo sobre a natureza humana, universalizando, assim, sua escrita, antes que isso fosse tendência adotada nos espaços nacionais mais eruditos.

\section{Um olhar sobre os estudos acerca da Cultura Popular}

Os estudos teóricos sobre a literatura popular ganharam relevância a partir do início do século XX, impulsionados pelas teorias antropológicas de Lévi-Strauss. Segundo Ginsburg (1976), foi nesse período que a consciência pesada do colonialismo se uniu à consciência pesada da opressão de classe e superou-se a concepção de folclore como coleção de curiosidades, mas também a posição de quem distinguia nas ideias e crenças, visões de mundo elaboradas séculos antes.

Porém, o interesse despertado pelas artes populares iniciou-se anteriormente, ainda no século XVIII. Naquele período não se buscavam desenvolver estudos teóricos acerca da literatura popular, mas tão somente resgatar tradições culturais. $O$ interesse por essas produções deu-se no momento de definição dos estados nacionais europeus, pois "a busca da identidade nacional passava obrigatoriamente pelo resgate das tradições populares coletivas" (GINSBURG, p. 43, 1976).

Esse período coincidiu com a Revolução Industrial, a Revolução Francesa e a urbanização da sociedade europeia, fatos que modificaram aquela região e, posteriormente, todos os continentes. O retorno às tradições populares, durante essa conturbada época, e o abandono das convenções clássicas propiciou discussões teóricas direcionadas à cultura popular. Esses estudos procuravam uma definição do termo popular. Burke (1989), historiador inglês, acredita que os 
escritores alemães foram os primeiros a criar uma série de termos para definir esse conjunto de tradições.

Nas obras de J.G. Herder e dos irmãos Grimm, observa-se essas concepções e valorizações. Para esses autores, a apropriação das culturas populares não era meramente uma questão de valorização estética dessas produções, buscava-se nelas um tipo de expressão que, segundo eles, estava em vias de desaparecer por conta da urbanização e do próprio processo civilizatório (HALL, 2003). A cultura popular, e mais precisamente a poesia popular, era interpretada como produção coletiva. Julgavam-na como um instrumento que poderia determinar a identidade nacional.

Algumas produções populares foram utilizadas, na época, a fim de criar sentimentos nacionalistas. Assim, a cultura popular serviu como "constituinte básico para a formação de uma unidade nacional, oferecendo a esta uma memória a ser compartilhada e símbolos suficientes capazes de produzir um eficiente nível de coesão social" (BURKE, p. 56, 1989). Cabe lembrar, no entanto, que essas culturas passavam por uma reelaboração. Eram adequadas aos objetivos de uma elite para tornarem-se parte de um processo não só cultural, mas político e econômico. O indianismo e o medievalismo, tendências românticas, exemplificam esse processo em território nacional.

Em diversas situações, a cultura popular resistiu ao poder simbólico hegemônico. Muitos povos, as minorias étnicas, ancoraram-se nas tradições negando a imposição do simbolismo dominante. Os curdos e os bascos, por exemplo, permaneceram como enclaves dentro de uma estrutura nacional (BURKE, 1989). Os iluministas percebiam o paradoxo, pois se "as culturas populares criavam identificações nacionais e fortaleciam o estado democrático, traziam consigo também um ímpeto anárquico e desestabilizador" (GINZBURG, 1976, p.36).

Os autores iluministas, inclusive, inferiorizavam o saber popular. Caracterizavam-no como avesso ao racionalismo. Apesar de apoiarem o discurso teórico na figura do povo, excluíam as estruturas populares de suas produções. Tudo que "proviesse das expressões populares acaba caracterizado como inculto pelo racionalismo burguês" (BURKE,1989, p. 58). Essa visão, na verdade, predominava, na sociedade europeia desde a supremacia da escrita sobre a 
oralidade, ocorrida ainda na Idade Média. A aristocracia, o clero e a intelectualidade, em geral, viam as produções populares como inferiores em relação à cultura erudita.

Porém, muitos como Canclini e Umberto Eco defendem a impossibilidade de discernir as culturas, categorizando-as. Esses teóricos acreditam numa troca constante de símbolos no campo cultural. Canclini (1983) nomeia de "circularidade cultural" a essa influência simbólica recíproca. A visão dinâmica dos teóricos no século XX alterou a percepção sobre as culturas de forma geral.

Em seu livro intitulado $A$ cultura popular na ldade Média e no Renascimento: o contexto de François Rabelais, Bakhtin (1992) documenta que seria mais fácil compreender os costumes populares do período medieval analisando as falas de Gargântua e Pantagruel, jamais lidas por um camponês, do que por um Almanach dês bergers, que circulava na época entre as classes populares. O intuito do autor é mostrar que, especialmente no século XVI, o influxo recíproco entre cultura subalterna e hegemônica foi intenso.

Após estudos teóricos como os de Bakhtim (2002), pode-se concluir que a troca simbólica permeia as culturas, sejam elas eruditas ou populares. Essa reciprocidade cultural é constatada em todas as produções. Porém, a pesquisa direta da obra popular, ao contrário do que foi feito em Gargântua e Pantagruel, aumenta a perspectiva de entendimento do discurso da classe popular, bem como os desejos e motivações do autor.

Porém, é intenção, neste artigo ater-se a uma produção de autor não pertencente diretamente a classe popular, mas compreender, principalmente, 0 processo de adaptação de uma narrativa popular a aspectos mais universais da literatura, como fez Simão Lopes Neto e tantos outros autores com o advento do Modernismo. Esta é uma das buscas na pesquisa: aproximar-se da linguagem e da temática de uma obra, analisando a apropriação nela do discurso popular, mas destacando nela seu valor mais universal.

\section{Uma rápida passagem pela biografia de Simão Lopes Neto}

A produção literária de Lopes Neto oferece barreiras linguísticas aos leitores, principalmente os Contos Gauchescos e as Lendas do Sul, mas a despeito 
disso o interesse pelo universo narrativo criado pelo escritor só cresce entre pesquisadores e até entre os leitores comuns, já que novas edições de suas obras são lançadas regularmente. Trabalhos acadêmicos de relevância também são desenvolvidos nas universidades, isso resulta de um processo natural na crítica literária, o de reposicionar mesmo que tardiamente autores relevados a uma posição inferior a merecida em décadas anteriores (ZALLA, 2010).

Mesmo após mais de 100 anos da morte de Simão Lopes Neto, ainda não foi possível reunir a obra completa do autor, o que se observa, no geral, entretanto, é uma visão progressista nas temáticas que ele aborda, desde livros didáticos para a educação de crianças da Educação Básica, até suas obras mais conhecidas, percebe-se que ele esteve atrelado a questões relevantes para o progresso da humanidade. Ele ainda produz em diversos gêneros, incluindo-se a narrativa literária, o texto jornalístico e aventurou-se também na produção de dramaturgia (AYALA, 1995).

João Simões Lopes Neto nasceu em 1865, na Estância da Graça, a maior charqueada do Rio Grande do Sul, distante 30 quilômetros do Centro de Pelotas. Seu avô, Visconde da Graça, foi o homem mais rico e poderoso da província naqueles dias. Sua primeira infância foi naquela região rural que lhe permitiu a convivência com a cultura popular, a memória e a linguagem oral, próprias dos moradores humildes que ali viviam (POZENATO, 2009).

$\mathrm{Na}$ adolescência morou, a fim de cumprir estudos, no Rio de Janeiro durante sete anos, onde teria estudado no Colégio Abílio e cursado Medicina, sem nunca concluir. Não se sabe muito sobre sua vida nesse período, mas como era herdeiro de família abastada e interessado pelas artes certamente frequentou teatros, cafés, livrarias e a Rua do Ouvidor, enquanto eclodiam os movimentos republicanos e abolicionistas, sendo esse o período em que Machado de Assis publicou Memórias Póstumas de Brás Cubas (AYALA, 1995).

Lopes Neto retorna ao Sul, entretanto jovem entusiasmado, moderno e cosmopolita, ele não queria somente administrar a parte que lhe coube da fortuna. A partir de 1980, inicia um empreendimento. Foi o primeiro dos muitos fracassos profissionais que o levaram à miséria. Já empobrecido e alquebrado pelos fracassos empresariais, o escritor entra na década de 1910 em plena atividade intelectual, escrevendo conferências, dando aulas e viabilizando a publicação de 
seu primeiro projeto na recolha de folclore, o Cancioneiro Guasca. Para sobreviver, foi trabalhar como redator remunerado nos jornais Correio Mercantil e A Opinião Pública. Falece em 1916 (ZALLA, 2010).

\section{Discussões teóricas sobre a produção literária Simão Lopes Neto}

Inúmeros debates acerca da obra de Simão Lopes Neto foram feitos ao longo das últimas décadas. Desde estudos mais superficiais que enquadram o autor como um Pré-modernista e representante do regionalismo gaúcho até outras mais aprofundadas, que o localizam em um espaço literário mais relevante, ao defenderem a universalidade de sua obra.

Doutor em História Social pela Universidade Federal do Rio de Janeiro e pesquisador da obra de Lopes Neto, o professor Jocelito Zalla (2010) afirma que o gaúcho produziu uma prosa de tema campeiro bastante diferente de contemporâneos seus como Roque Callage (1929), pois "ele criou uma literatura diferente, na qual se desviou da norma culta da língua portuguesa para dar voz a um personagem daquele mundo popular, Blau Nunes (2010, p.07)".

Pozenato encontra fartos exemplos da distância entre Simões e seus contemporâneos, celebrados à época como escritores mais qualificados para retratar a matéria rural rio-grandense e enquadrados aos anseios da elite da época. Segundo Pozenato (2009, p.56): "A narrativa em primeira pessoa é feita por uma voz popular, por um homem do campo, neto de avó charrua. Só isso já representa uma mudança radical na perspectiva da obra, uma inovação estética sem precedentes por aqui".

Chaves (2001, p. 129) chama a atenção para os aspectos da linguagem e da riqueza vocabular: "Simões Lopes parece ter desenterrado um léxico perdido de há muito no chão da campanha; pôs na boca do peão cousas esquecidas; ressuscitou termos; expressões e modismos do tempo em que as fronteiras do Sul oscilavam dia a dia, conforme a estrela das armas portuguesas ou castelhanas". Por isso, grande parte do mérito do autor reside na voz narrativa de Blau Nunes, o ancião vaqueiro, de 88 anos, o que confere verossimilhança à obra, posto que lança mão da autoridade da testemunha.

Chaves (2001, p. 170) ao referir-se ao uso do regionalismo na produção do autor assim se refere: "O dado fundamental para a interpretação da obra simoniana 
não é a sua inclusão no regionalismo mas o fato de que, incorporando-o, tenha conseguido dialeticamente ultrapassá-lo para expressar uma visão de mundo". O autor percebe que a relevância dada à condição humana e suas contradições na temática de Simão Lopes Neto eleva a produção do autor a outro patamar de discussão, que excede uma produção puramente popular. Ayala (1995) relembra, então, que o verdadeiro mote dos contos é a situação-limite, trazendo à tona a dimensão humana e, portanto, nas palavras do autor, universal.

Segundo Calvino (1993), uma das características da obra universal é que "nunca esgota tudo o que tem a dizer a seus leitores", o fato de Simão Lopes Neto, a despeito da dificuldade da linguagem adotada nas narrativas e dos problemas decorrentes de organização de toda sua obra, continuar a arrematar a curiosidade de mais e mais leitores e também pesquisadores, cujos trabalhos permitem vislumbrar a qualidade de sua produção, atesta a afirmação de Calvino.

A fim de especificar melhor o que pretende este artigo, que é demonstrar como Simão Lopes Neto articula a linguagem e a cultura populares em uma obra de valor universal, far-se-á a análise mais detidamente do conto O Boi Velho.

\section{O popular e o universal em "O Boi Velho"}

O conto O Boi Velho integra o livro mais popular de Simão Lopes Neto, Contos Gauchescos (1912). Toda a obra faz clara referências ao emaranhado de histórias próprias da região Sul: os animais, os instrumentos, a paisagem, a rusticidade, o gaúcho estão ali representados, e todos eles possuem caráter regional. Esse conjunto de elementos esteve presente na vida do autor desde a tenra infância (BARBIERI, 1997), mas a intenção deste trabalho é demonstrar como a essência da temática da obra ultrapassa essa mera conceituação. Isso ocorre também na linguagem adotada pelo escritor, que segundo Barbieri (1997, p. 35):

Rompeu o cerco do regionalismo de dentro do regionalismo. Trabalhando não só o modo de viver mas, igualmente, o modo de dizer do gaúcho típico dos pampas, Simões verticalizou a sua inquirição regionalista de modo a fazer aflorar em seus textos motivos transregionais sem, em nenhum momento, perder o colorido da regionalidade. É como se Simões, perfurando com instrumento linguístico percuciente as camadas das tradições e dos mitos gauchescos, tivesse feito sangrar do subsolo regionalista veios que dele transbordam. [...] 
Ao fazer tal uso da linguagem, Simões afirma-se de maneira nova, pois desgasta por dentro o próprio regionalismo. Não basta dizer que faz um regionalismo diferente. Ele rompe com os limites que confinam a literatura regionalista no "círculo estreito de seus maneirismos e sestros" (BARBIERI, 1997, p. 37).

O conto a ser analisado neste trabalho é narrado por um ancião, Blau Nunes. A presença desse narrador resolve um problema literário do período, no que se refere ao aproveitamento da temática e linguagem populares em contos ou romances até então. Com Blau Nunes, sai de cena o narrador cujos saberes podem ser considerados muito eruditos, quando postos à frente de experiências populares e surge o contador, cuja trajetória contextualiza-se em meio ao povo, e esse recurso passa a conferir verossimilhança ao que é narrado. A adoção desse recurso foi inovador do ponto de vista literário na época.

O narrador de Contos Gauchescos, e especificadamente do conto O Boi Velho, é um velho vaqueiro de 88 anos, cuja carência no campo acadêmico em nada atrapalha sua capacidade de condução narrativa, pelo contrário. Blau Nunes é um gaudério, um homem que tem de seu apenas o cavalo e as habilidades campeiras e guerreiras, mas carrega um conjunto muito vasto das experiências que acumulou durante sua lida.

Socialmente, ele pertence ao núcleo inferiorizado da sociedade, segundo ele aos "de baixo" e que olha para os "de cima" com certa desconfiança, pois já vivera o bastante para compreender o funcionamento das coisas e a natureza das pessoas.

Em O Boi Velho, um dos tantos contos que ele narra, a temática principal é a maldade de estancieiros, mas se pode concluir com muita rapidez, ainda no início, que, na verdade, a intencionalidade literária é conduzir o interlocutor a uma reflexão sobre a natureza da maldade, pois apesar de narrar acerca do trágico fim de um animal, decorrido de atitudes cruéis de uma família de estancieiros, logo na primeira parte da história temos uma afirmativa que universaliza a maldade caracterizandoa como sentimento inerente à natureza humana, não somente das personagens ali descritas: "Cuê-pucha!... é bicho mau, o homem!" (LOPES NETO, 2006, p. 67), diz o vaqueiro. 
Fernando Pessoa (2019), sobre isso, citou que um livro se torna clássico por falar essencialmente de sentimentos humanos, que são os mesmos em qualquer parte do mundo, assim, facilitando a identificação com a mensagem ali inserida. Isso posto, percebe-se que apesar da temática, que parece banal, ou da linguagem com fortes cores regionais, o que se conta nessa história atinge a todos os homens, pois se discute tema relacionado a valores e atitudes humanas e universais.

Diante do impacto da primeira fala, fica inegável que Blau Nunes se refere à maldade humana como marca da natureza, inerente à existência dos homens sobre a terra. Toda a história que se segue vai servir de argumento a fim de se comprovar essa tese, que soa como universal, apesar de contextualizada na narrativa a uma determinada sociedade.

Adiante, o narrador traz o ouvinte para o centro da história, ao se utilizar da digressão, esse recurso aumenta o interesse pelos fatos, uma vez que soa como um convite para uma melhor reflexão do texto ouvido: "Conte vancê as maldades que nós fazemos e diga se não é mesmo! Olhe, nunca me esqueço dum caso que vi e que me ficou cá na lembrança, e ficará té eu morrer" (LOPES NETO, 2006, p. 67). Note-se também, no trecho, o interesse em dramatizar ainda mais a situação, quando Blau Nunes afirma que o fato marcou-o de modo perene.

Segundo Ítalo Calvino (1993), uma das características de uma obra universal reside no fato de que sua narrativa ultrapassa seu tempo, persistindo de alguma maneira na memória coletiva e sendo atualizada por sucessivas leituras, no transcurso da história. A relevância que a história possuiu em toda a trajetória de Blau Nunes, não sabemos ao certo que idade tinha quando a presenciou, também universaliza a narrativa, uma vez que o autor deixa clara a forma como o fato encontra-se incrustado em sua memória, ou seja, marcado até seus últimos dias.

Apenas após a apresentação de uma tese acerca da natureza humana e de preparar o leitor para o impacto do que será narrado é que se apresentam o espaço e as personagens que compõe o conto, quando o narrador afirma que tudo ocorreu "na estância dos Lagoões, duma gente Silva, uns Silvas mui políticos (LOPES NETO, 2006, p. 67)", observa-se, nesse ponto, que existe uma desumanização, logo de princípio, das personagens. Além de serem apresentadas 
apenas pelo sobrenome, e este ser acompanhado de artigo indefinido, também se deixa relevante 0 interesse pessoal e valores de classe daquela família "que sempre (estaria) metida em eleições e enredos de qualificações de votantes (LOPES NETO, 2006, p. 67)".

Para que uma história se faça universal, segundo Ítalo Calvino (1993, p.134), não se faz necessário que ela seja um retrato meramente histórico de fatos ou de pessoas, pois "quanto mais explícita for a revelação histórica, menor o resultado estético. Na verdade, o espírito da época deve estar inserido na experiência dos indivíduos". Blau Nunes revela esse espirito a que se refere Calvino ao descrever de maneira tão sucinta e ampla a postura social daquela família.

O que se observa logo após é o contraste entre a caracterização que se fez da família e o ambiente que a rodeia, mas que também lhe pertence. Ao descrever a natureza exuberante da região Sul, a qual Simão Lopes conhecia tão bem, faz-se uso de linguagem regional peculiar e uso literário criativo da pontuação, permite-se também perceber a mudança de tom do narrador, que abandona sua visão sarcástica e expressa claramente emoção, Blau Nunes cria no interlocutor sensações próprias da poesia, ao falar da terra que conhece tão bem, mesmo que o faça no interior de uma narrativa. Segundo Calvino (1993), uma obra universal utiliza-se da linguagem de uma maneira exemplar, original e inesperada, e isso fica bem claro no trecho:

\begin{abstract}
A estância era como aqui e o arroio como a umas dez quadras; lá era o banho da família. Fazia uma ponta, tinha um sarandizal e logo era uma volta forte, como uma meia-lua, onde as areias se amontoavam formando um baixo: o perau era do lado de lá. O mato aí parecia plantado de propósito: era quase que pura guabiroba e pitanga, araçá e guabiju; no tempo, o chão coalhava-se de fruta: era um regalo! (LOPES NETO, 2006, p. 68)
\end{abstract}

Após essa descrição amplamente poética, segue-se a apresentação de outras duas personagens, essas sim nomeadas, curiosamente dois animais, especificadamente, bois: "Um se chamava Dourado, era baio; o outro, Cabiúna, era preto, com a orelha do lado de laçar, branca, e uma risca na papada (LOPES NETO, 2006, p. 68). Os animais pertenciam à família e puxavam o carretão, típico carro de boi da região, que levava as mulheres e as crianças aos banhos diários e outros afazeres. 
Quanto ao uso do tempo na narrativa, ele se faz perceptível como cronológico principalmente pela frase "Assim correram os anos, sempre nesse mesmo serviço" (LOPES NETO, 2006, p. 68), no caso, referindo-se aos bois e a sua rotina de ir e vir com a família, servindo-a de acordo com as necessidades. Da descrição, depreende-se que a história da família e dos bois parece ser inseparável, uma vez que algumas gerações nasceram e cresceram junto a eles.

Inclusive, Blau Nunes, conta algumas passagens dos animais com a família ao afirmar que os bois, muito mansos, serviam também como diversão para as crianças, que ainda imbuídas de inocência agradavam e brincavam com os animais (LOPES NETO, 2006). Mas o tempo passa e as crianças acabam por se moldar ao comportamento dos pais e da classe, no caso "os de cima", e para estes cujo interesse sempre foi o econômico, a velhice dos bois acaba por desvalorizá-los, uma vez que o que sobressai é o valor do dinheiro que vai de encontro à condição da velhice.

O primeiro a falecer é Dourado: "Um dia, no fim do verão, o Dourado amanheceu morto, mui inchado e duro: tinha sido picado de cobra (LOPES NETO, 2006, p. 68). Nesse ponto, o narrador avança na humanização dos bois ao descrever a aflição de Cabiúna, como Blau Nunes é um velho vaqueiro e seu ofício viver em meio a esses animais, a narrativa ganha mais verossimilhança:

Cabiúna; como era mui companheiro do outro, ali por perto dele andou uns dias pastando, deitando-se, remoendo. Às vezes esticava a cabeça rara o morto e soltava um mugido... Cá pra mim o boi velho - uê! tinha caraca grossa nas aspas! - o boi velho berrava de saudades do companheiro e chamava-o, como no outro tempo, para pastarem juntos, para beberem juntos, para juntos puxarem o carretão, ...Que vancê pensa! ... os animais se entendem... eles trocam língua! ... (LOPES NETO, 2006, p. 68)

Revestir os animais de humanidade acabou sendo comum a obras posteriores do Modernismo brasileiro, João Guimarães Rosa produziu boa parte de seus contos personificando animais, o mesmo caminho faz Graciliano Ramos com a cachorra Baleia, cujas percepções acerca da realidade superam a dos humanos em Vidas Secas, podemos afirmar, sem nenhuma dúvida, que em nada Simão Lopes deve em relação aos dois grandes expoentes do Modernismo supracitados. Segundo Calvino (1993), uma obra universal pode ser assim conceituada quando cria formas de expressão inusitadas, originais e de grande 
repercussão na própria história literária. Considera-se que Simão Lopes alcança essa condição ao personificar e garantir aos bois a centralidade na narrativa, o que foi amplamente feito posteriormente.

A situação de Cabiúna é narrada em cores dramáticas, quando se descreve o final cruel dado aos restos mortais do companheiro: "Quando o Cabíúna se chegava mui perto do outro e farejava o cheiro ruim, os urubus abriam-se, num trotão, lambuzados de sangue podre, às vezes meio engasgados, vomitando pedaços de carniça..." (LOPES NETO, 2006, p. 68), Blau Nunes parece, neste conto, entregar ao interlocutor uma narrativa mais cruel do que este espera, conduzindo-o a um limite no campo da dramaticidade. Ao envelhecer, e dada as relações baseadas no lucro que habitualmente aquela família tinha, o boi vai ficando de lado, abandonado, pois outro carretão fora formado por animais mais jovens (LOPES NETO, 2006). Infeliz, o animal sai pelo mato. Tempos depois, ao reaparecer, sua magreza foi notada e em meio a conversas, a família decidiu que era "melhor matar-se aquele boi, que tinha caraca grossa nas aspas, que não engordava mais e que iria morrer atolado no fundo dalguma sanga e... lá se ia então um prejuízo certo, no couro perdido... (LOPES NETO, 2006, p. 69)". Aqui já se entende plenamente a maldade a que se referiu Blau Nunes no início da narrativa, mas o narrador vai além.

Segue-se a descrição fiel de como o boi foi amarrado e golpeado por um peão à frente de toda aquela gente que havia passado a infância com ele e crescido passeando alegremente sobre o carretão. Segundo o narrador ouve "um silenciozito em toda aquela gente (LOPES NETO, 2006, p. 69)" seguido de uma cena que, finalmente, vem a responder o porquê de Blau Nunes afirmar "nunca esquecer" o que vira.

O boi velho sentindo-se ferido, doendo o talho, quem sabe se entendeu que aquilo seria um castigo, algum pregaço de picana, mal dado, por não estar ainda arrumado. . . - pois vancê creia!-: soprando o sangue em borbotões, já meio roncando na respiração, meio cambaleando, o boi velho deu uns passos mais, encostou o corpo ao comprido no cabeçalho do carretão, e meteu a cabeça, certinho, no lugar da canga, entre os dois canzis ... e ficou arrumado, esperando que o peão fechasse a brocha e Ihe passasse a regeira na orelha branca...E ajoelhou ... e caiu ... e morreu... (LOPES NETO, 2006, p. 69)

Ainda aparece ao final um peão a carnear a carne do boi a fim de lhe tirar o couro, a razão de toda aquela maldade, e a presença de uma criança bem 
pequena, que mal consegue falar, a bater no boi morto enquanto lhe grita: "- Tome, tabiúna! Nó té... Nó fá bila, tabiúna! ..." (LOPES NETO, 2006, p. 69), a criança já trazia introjetada a maldade e sempre que tivesse oportunidade a distribuiria "aos de baixo", como Blau Nunes gostava de dizer.

Ao finalizar a narrativa, o vaqueiro retoma a conversa com o interlocutor ao repetir aquilo que já deve estar marcado na consciência de quem o ouviu "Veja vancê, que desgraçados; tão ricos.. e por um mixe couro do boi velho! (LOPES NETO, 2006, p. 69)", a certeza da declaração final do vaqueiro demarca que a narrativa será capaz de deflagrar na consciência do ouvinte alguma reação, e isso também faz dela algo de valor universal, segundo Calvino (1993).

\section{Conclusão}

O início do século $\mathrm{XX}$, apesar de marcado por inúmeras inovações no campo artístico-literário só vem a causar um real impacto na sociedade brasileira com a Semana da Arte Moderna, entretanto autores já se debruçavam sobre novas formas de lidar com a arte e com o fazer literário antes dela. Simão Lopes Neto foi certamente um deles.

Cada vez mais relevante nacionalmente, o autor finalmente demarca merecidamente seu espaço na literatura nacional. Ao unir a linguagem e a temática da sua região a temas de valores universais, tratando tudo isso a partir de um olhar progressista, o autor eleva a cultura popular a outro patamar artístico e direciona novas experimentações no campo da produção literária em sua época.

Em O Boi Velho, sem abrir mão da subjetividade, ele toca em temas relacionados à natureza humana, relacionando-os a um certo estrato da população, que ele mesmo conhecera, filho de estancieiro que foi. Tocado pelas letras, ele direciona seu olhar para o lado oposto, para "os de baixo", tomando como metáfora dos marginalizados o boi Cabiúna, mas ao tratar de assunto tão amplo e universal que é a maldade humana, não abandona os regionalismos e nem as cores da sua terra.

Entretanto, como se demonstrou, somadas à temáticas e à linguagens populares, ocorre também, na prosa de Simão Lopes Neto, a presença da sensibilidade, do trato característico com a linguagem, e de uma maneira individual, 
um olhar próprio em relação aos fatos e às coisas, que autorizam a afirmar que a produção literária do gaúcho pode ser caracterizada como universal, elevando as discussões sobre seus textos a um patamar diferente do que foi tratado pela crítica especializada em outros momentos.

\section{Referências}

AYALA, Marcos; AYALA, Maria Ignez Novais. Cultura popular no Brasil. São Paulo: Ática, 1995.

BAKHTIN, Mikhail. A Cultura Popular na Idade Média e no Renascimento: o contexto de François Rabelais. SP, Hucitec e Brasília, Universidade de Brasília, 1987.

BARBIERI, Therezinha. Colonização a ferro e fogo. In: REMÉDIOS, Maria Luíza Ritzel (Org.). Josué Guimarães: o autor e sua ficção. Porto Alegre: UFRGS, 1997.

BURKE, Peter. Variedades de história cultural. Rio de Janeiro: Civilização Brasileira, 2000.

CALLAGE, Roque. No fogão do gaúcho. Porto Alegre: Globo, 1929.

CALVINO, I. Por que ler os clássicos. In: Por que ler os clássicos. São Paulo: Companhia das Letras, 1993.

CANCLíNI, Nestor Garcia. As culturas populares no capitalismo. São Paulo, Brasiliense. 1983

CHAVES, Flávio Loureiro. Simões Lopes Neto. 2. ed. rev. Porto Alegre: UFRGS, 2001.

ECO, Umberto. Apocalípticos e Integrados: Debates. 2. ed. São Paulo: Perspectiva, 1976.

GINSBURG, Carlo. O queijo e os vermes. São Paulo: Companhia das Letras, 1976.

HALL, S. A identidade cultural na pós-modernidade. Trad. Tomaz Tadeu da Silva e Guacira Lopes Louro. 7.ed. Rio de Janeiro: DP\&A, 2003.

LOPES NETO, João Simões. Contos gauchescos e Lendas do Sul. Organização de Aldyr Garcia Schlee. Porto Alegre: Instituto Estadual do Livro: UNISINOS, 2006. vol. 1.

PESSOA, Fernando: poemas e fingimentos / Lígia Militz da Costa. - Guaratinguetá, SP: Penalux, 86 p. 2019.

POZENATO, José Clemente. O regional e o universal na literatura gaúcha. Caxias do Sul: EDUCS, 2009. 
REGO, Ligia M.S., BRAGA, Angela C. Ícones da Arte. 2002. Disponível em: . Acesso em: 23 jun. 2008.

ZALLA, Jocelito. Quando a literatura fala à história: a questão indígena missioneira na obra de Barbosa Lessa e o "Caso Sepé" no Rio Grande do Sul dos anos 1950., 2010.

Disponívelemhttp://www.eeh2010.anpuhrs.org.br/resources/anais/9/1279506362_ ARQUIVO_QuandoaLiteraturafalaaHistoriaJocelitoZalla.pdf. Acesso em: $1^{\circ}$ março de 2020. 